\title{
EL EXILIO Y SU IMPACTO EN LA REFORMULACIÓN DE PERSPECTIVAS IDENTITARIAS, POLÍTICAS E INSTITUCIONALES ${ }^{1}$
}

\author{
EXILE AND ITS IMPACT ON SHIFTING PERSPECTIVES ON \\ POLITICS, INSTITUTIONS AND COLLECTIVE IDENTITIES
}

\section{Luis Roniger*}

\section{RESUMEN}

El exilio es un mecanismo institucionalizado de exclusión política que ha sido ampliamente usado en toda Iberoamérica. Este trabajo intenta analizar su impacto en la reformulación de perspectivas políticas e institucionales. Es en el extranjero que ciudadanos desplazados de su territorio nacional han redefinido compromisos políticos y han reformulado visiones que han impactado los países de origen. El trabajo elabora esa dinámica del exilio con base en casos históricos y recientes de exiliados políticos, destacando sus aportes a la reformulación del horizonte colectivo de las sociedades latinoamericanas.

PALABRAS CLAVE: AMÉRICA LATINA * ASILO * EXILIO * ASPECTOS PSICOLÓGICOS * IDENTIDAD $*$ DESARROLLO POLÍTICO $*$ PROYECTO POLÍTICO

\section{ABSTRACT}

Exile is an institutionalized mechanism of political exclusion, which has been used throughout Latin America. This article aims to analyze its impact on the reformulation of political and institutional perspectives. It is abroad that citizens forced out of a national territory redefine political commitments and rephrase collective visions, with an impact on the countries of origin. Based on historical and more recent cases of forced displacement, this work stresses the contribution of political exiles to the redefinition of the collective horizons of the Latin American societies.

KEY WORDS: LATIN AMERICA * ASYLUM $*$ EXILE $*$ PSYCHOLOGICAL ASPECTS $*$ IDENTITY * POLITICAL DEVELOPMENT * POLITICAL PROJECT

1 Una primera versión de este trabajo fue presentada en el congreso de la Latin American Studies Association (LASA) en Rio de Janeiro, 11-14 de junio de 2009 y elaborada durante una residencia de investigación en el Instituto de Altos Estudios (IAS) de la Universidad Hebrea de Jerusalén, en febrero-julio de 2009. El autor agradece la asistencia de Orly Haimovich en la preparación del trabajo.

* Reynolds Professor of Latin American Studies en Wake Forest University, EUA.

ronigerl@wfu.edu 


\section{INTRODUCCIÓN}

El exilio es un mecanismo institucionalizado de exclusión política que ha sido ampliamente usado y abusado en toda América Latina, a lo largo de los dos siglos de vida estatal independiente. En años recientes, los estudios de exilio han contribuido al análisis que trazan el contexto institucional y sociopolítico que generó exilios en la región en forma recurrente, así como un entendimiento de sus transformaciones (vg. Yankelevich y Jensen, 2007; Roniger y Sznajder, 2008; Sznajder y Roniger, 2009). De manera similar, tales estudios - combinados con una miríada de testimonios de exiliados de la última ola represiva- han iluminado distintos aspectos de las experiencias personales $y$ de las comunidades de exiliados, especialmente de aquellas que congregaron a desplazados en el período de la Guerra Fría, bajo la represión de las dictaduras en América del Sur y América Central (Rollemberg, 1999; Yankelevich, 2004; Yankelevich y Jensen, 2007; White y Oñate, 2007; Dutrénit, Allier Montaño y Coraza de los Santos, 2008; Franco, 2008).

Este trabajo se apoya en tales estudios, planteando que el exilio debe también ser analizado como una variable independiente, en su impacto colectivo sobre las sociedades y la política latinoamericana. Ello es así pues el exilio implica un proceso de transformación personal y colectiva, pleno de ambigüedad, que se inicia cuando los exiliados se ven forzados a abandonar su país de origen $y$ en muchos casos no termina ni aún tras el retorno al país de origen. Para trazar las consecuencias colectivas del exilio, el trabajo se concentra en el impacto del exilio en la redefinición de aspectos fundamentales de la política en la región: las visiones políticas; las concepciones de institucionalidad; y las identidades colectivas, tanto nacionales como transnacionales. Por razones de espacio, el trabajo no pretende ser exhaustivo en torno al contexto de la expulsión, sino que analiza el impacto del destierro en la formación y reformulación de estos aspectos cruciales de la vida en los estados latinoamericanos.

\section{IMPACTOS FORMATIVOS DEL EXILIO}

A menudo, el destierro fue secuela de la derrota de proyectos políticos. El exilio ha forzado a los desterrados a repensar compromisos políticos e identidades, visiones colectivas $y$ prácticas institucionales. El mero destierro ha implicado a menudo la vivencia de reconocerse extranjero/a en tierras extrañas, aun cuando los países de recepción - $-y$ en décadas recientes organismos internacionales como el ACNUR - reconocieran la condición de asilado/a o refugiado/a.

En tempranas etapas de configuración de los estados nacionales en América Latina, fue a menudo el destierro de los próceres y sus redes lo que puso en evidencia el cambio de identidades $y$ jurisdicciones que se estaba operando en momentos de disgregación del imperio español. Un caso evidente fue el de los hermanos Carrera, parte de la aristocracia que habían dirigido la República Vieja (1810-14) en Chile y que, una vez desplazados por Bernardo de O'Higgins, se trasladaron a Cuyo, que en un pasado no lejano había sido parte de la Capitanía General Chile, antes de pasar a conformar parte de la jurisdicción del Virreinato de Buenos Aires en 1778. Una vez en Cuyo, los Carrera se encontraron bajo la emergente soberanía de Buenos Aires en la figura del gobernador José de San Martín, quien - aunque abocado a preparar la futura liberación de Chile- no se sometió a los aires de supremacía de los Carrera. Sobre tal trasfondo de confrontación de personalidades, soberanías e identidades, los hermanos Carrera orquestarían fallidos intentos de golpe contra O'Higgins hasta ser condenados a muerte, generando nuevos ciclos de violencia de parte de los deudos y las fuerzas que los apoyaban, lideradas por José Miguel Carrera hasta su muerte en 1821 (Encina, 1947, vol. 7: 528-531). Similares efectos tuvieron los exilios de bolivianos y peruanos en el contexto de los distintos proyectos de control estatal o establecimiento de confederaciones en el área andina. En este caso también, los desterrados contribuyeron a la delimitación de territorios y la definición de las naciones $y$ los estados tal como los conocemos hoy (Sznajder y Roniger, 2009: 67-72). Al 
igual, en el área de América Central, el exilio -y en el caso de muchos, la muerte- de líderes del movimiento unionista de principios del siglo XIX signó la suerte de la Confederación de Centroamérica, que fue reemplazada a partir de 1839 por estados soberanos fragmentados del seno del estado del Istmo (Dym, 2006).

Los exiliados jugaron un rol importante en dicho proceso de establecimiento de tempranas soberanías $y$ futuras 'comunidades imaginadas', en los términos de Benedict Anderson. Pero el proceso se inicia aún antes de la independencia, cuando los Jesuitas desterrados a Europa en la segunda mitad del siglo XVIII recrearon los paisajes naturales y humanos de las tierras americanas, con un patriotismo que luego de la independencia habría de ser considerado - desde perspectivas constructivistas y anacrónicas - una forma inicial de 'nacionalismo'. En 1759, el primer ministro portugués Marqués de Pombal y la corona portuguesa decidieron la expulsión de los jesuitas de sus dominios. Ocho años más tarde, el 20 de agosto de 1767, Carlos III emitía una orden similar de expulsión de los jesuitas del imperio español. Las autoridades utilizaron grandes fuerzas del ejército para aplicar la decisión en la América española (Hollis, 1968; Moerner, 1965; Giménez López, 1997). Más de cinco mil jesuitas fueron expulsados, la mayoría en Italia, donde se abocaban al trabajo académico y la escritura bajo la supervisión de la Iglesia. Un 14 por ciento de ellos abandonaron la Orden hasta 1773, como un primer paso para poder regresar a la patria. Otros miembros de esta culta élite usaron su trabajo académico y acceso a los archivos y bibliotecas en Bolonia, Ferrara, Modena, Roma, Florencia, Génova, Milán, Nápoles y Venecia para entrar en debate con una serie de estudiosos europeos que denigraban la imagen de las Américas sin conocerlas. Se trataba de escritores como Corneille de Pauw, William Robertson y Guillaume-Thomas Raynal, que retrataban las Américas como una réplica débil de Europa (Gerbi, 1996).

Enfrentados a un clima intelectual hostil y bajo la percepción de la parcialidad de las ideas europeas sobre las tierras americanas, los jesuitas exiliados en Europa escribieron obras en las que trataron de presentar la riqueza de su patria americana: las tradiciones, la historia, las antigüedades, la fauna, la flora, el clima y la geografía. Algunas de las obras más conocidas son las de Juan de Velasco, un ecuatoriano jesuita que durante su exilio en 1788 escribió La historia del Reino de Quito; Juan Ignacio Molina, un jesuita de Chile, quien escribió la Historia Geográfica, Natural y Civil del Reino de Chile (1782-7); y Francisco Javier Clavijero, autor de la Historia Antigua de México (1780-1) (Brading, 1993: 447-464).

Si bien estas obras fueron ordenadas por los superiores jesuitas, dieron lugar a la expresión de distintos sentimientos de patriotismo. Clavijero dedicó su trabajo a la universidad de México, lamentando la separación de su patria $y$ alegando que su obra era 'una historia de México escrita por un mexicano'. Velasco lanzó un feroz ataque a la 'secta moderna de filósofos anti-americanos' y sus quiméricas ideas (Clavijero, 1943: 3; Velasco, 1981; Brading, 1993: 447). Estos jesuitas profesaron un profundo amor a la patria que dejaron atrás, estando profundamente influidos por la Ilustración y la revolución científica, la historia y la filosofía. Si bien no fueron los primeros jesuitas en escribir sobre América (por ejemplo, Alonso de Ovalle a mediados del siglo XVII), su destierro en Europa contribuyó al desarrollo de un patriotismo, indicador de la cristalización territorial de las identidades colectivas, que en breve iniciarían la formación de naciones-estado.

Luego de la independencia, no pocos intelectuales exiliados se abocaron a la misma tarea, pero ya desde la perspectiva de repensar la nacionalidad y reformar aquellos estilos de hacer política que provocaron su propio destierro. Entre quienes intentaron contribuir a partir de su experiencia a la elaboración nacional se destaca el caso de Benjamín Vicuña Mackenna, un intelectual chileno del siglo XIX cuya experiencia exiliar lo llevó a dedicar energías a la historiografía. A través de sus libros y su presencia pública en la prensa y discursos aportó una importante contribución a la construcción de una moderna identidad nacional chilena.

De joven, Vicuña Mackenna era un Liberal que pretendía combinar su capacidad 
creativa con el activismo de un actor político y participó en dos revueltas contra el régimen conservador en la década del 50 del siglo XIX. Pronto se vio obligado a abandonar su país de origen, en primer lugar entre noviembre de 1853 y octubre de 1855, y por segunda vez entre marzo de 1859 y enero de 1861 (Rénique, 2009). En su derrotero en el exilio, Vicuña Mackenna viajó a través de las Américas y Europa, viajes que afinaron sus interrogantes respecto del Chile natal. En las palabras de José Luis Rénique:

Del destierro, asimismo, derivarían las grandes preguntas que a través de los decenios de 1860 y 1870 estimularían su labor intelectual: ¿Qué posibilidades podría Chile tener en un mundo de naciones crecientemente dominado por el dinamismo yankee? ¿Cómo, desde el extremo del Pacífico Sur, aquel pequeño desprendimiento del Imperio español que era Chile podía convertirse en un miembro efectivo, competitivo $y$ digno de respeto, de esa emergente globalización? ¿Qué materiales, qué tradiciones, podrían permitir la elaboración de una voluntad nacional capaz de sobrepasar las limitaciones que acechaban a la «chilenidad»? (Rénique, 2006).

Estas cuestiones saltaron a su vista al comparar la realidad chilena con la situación en los países que recorrió en su exilio. Al visitar México y Brasil, Vicuña Mackenna fue muy crítico de la composición étnico-demográfica de estos países que en su opinión etnocéntrica se habían contaminado por el componente indígena y de origen africano de la población. También llegó a la conclusión de que Chile debería hacer emprender una amplia iniciativa de colonización, a fin de superar las tendencias retrógradas, atributo de la población indígena local. Su imagen de los Estados Unidos fue igualmente negativa pero por razones diferentes, a saber, a causa de las tendencias materialistas y la vulgaridad que percibió y que contrastaba con la más culta y aristocrática cultura de fondo de las élites chilenas. También Europa lo decepcionó, sobre todo por la suciedad y la pobreza de Roma - que contrastaba con su clásica imagen y su pasado glorioso-y la distancia social entre las masas brutalizadas y la omnipotente aristocracia en el Reino Unido. Vicuña Mackenna regresó del exilio con la plena confianza de que un Chile dinámico e integrado podría mirar hacia el futuro "sin temor ni sentimientos de inferioridad". Al reflexionar sobre Chile bajo el trasfondo de países más grandes como México y Brasil, consideró que las tendencias históricas de su país permitirían una excepcional estabilidad económica y política, lo que podría hacer de esa nación un país líder en las Américas.

Entre quienes se exiliaron en Europa ya en pleno siglo XIX, cuando los estados latinoamericanos ya poseían presencia institucional, hubo quienes intentaron repensar a toda la región, re-elaborando ideas confederativas o bien proyectando la idea de América Latina a un plano cultural. Por ejemplo, la propia idea de una América "Latina" fue lanzada por exiliados como José María Torres Caicedo, un escritor e intelectual nacido en Bogotá en 1830 y que, a partir de su expatriación, contribuyó a la formación de la imagen de América Latina. A los 17 años, comenzó una carrera de periodismo político, pero pronto descubrió los límites de la libertad de expresión en Colombia. Desde mediados de 1849 editó un diario opositor, $E l$ Día, cuyo equipo tipográfico fue destruido en un motín, probablemente apoyado o incluido ideado por el gobierno. Sus posiciones políticas lo condujeron asimismo a un duelo, en el que recibió un disparo en 1850. A la edad de 20 años, partió de Colombia hacia París, donde tenía la intención de recuperarse de sus heridas. Se convirtió entonces en un expatriado que, salvo visitas cortas a la patria, residió en el extranjero hasta su muerte en 1889 (http://www.famousamericans.net/jose mariatorrescaicedo/) [14 de Junio de 2006].

En Europa, Torres Caicedo llegó a representar a su país en Londres y París, fue cónsul general de Venezuela y encargado de negocios en Francia y los Países Bajos, y más tarde fue encargado de negocios de El Salvador en Francia y Bélgica. Pero aun más importante, desde la distancia de un océano, elaboró 
un enfoque continental sobre los países de las Américas. Fue uno de los primeros en lanzar, a más tardar en 1856, el término de América Latina como un denominador común para los territorios hispanos, portugueses y franceses del nuevo continente ${ }^{2}$. "Nos encanta nuestro país con pasión", dijo en 1864, "y sin embargo, consideramos a la hermosa tierra de América Latina como una patria común”. Siendo un prolífico escritor y crítico literario en París, llegó a desempeñar un importante papel en la Asociación Literaria Internacional fundada allí en 1878 y dirigida por Víctor Hugo, en cuyo seno proyectó la voz de todo un continente. Apoyó la idea de una Unión Latinoamericana, que adelantara en un libro con ese título escrito en 1864, e incluso fundó una asociación con ese fin.

Otro ejemplo destacado de lo que podríamos denominar (a falta de un término mejor) pan-nacionalismo es el de Eugenio María de Hostos y Bonilla (1839-1903). Nativo de Puerto Rico, bajo dominio colonial español hasta 1898, Hostos prevé una federación de las naciones de las Antillas, mientras se asentaba en la República Dominicana y la tornaba su patria adoptiva. Hostos produjo un conjunto de obras historiográficas de inclinación liberal que fueron formativas, influyendo en toda una joven generación de intelectuales e historiadores dominicanos, dedicados al estudio de su sociedad después de 1880 .

Hostos se había educado en derecho en España, un país que abandonó en 1869, desilusionado por la falta de apoyo de los republicanos españoles para con la independencia de Puerto Rico. Al partir, no regresó a su país de origen, sino que se transformó en una especie de expatriado errante. Se trasladó entonces a la ciudad de Nueva York y se convirtió en un miembro de la Junta Revolucionaria de Cuba. Poco después, se fue a un viaje de cuatro años por Colombia, Perú, Chile, Argentina y Brasil, donde hizo campaña por la independencia de

2 Hay incertidumbre con respecto al año de acuñación de la expresión. Torres Caicedo menciona la fecha de 1851, pero los investigadores no han podido corroborar esto en sus escritos hasta 1856 por primera vez.
Cuba y Puerto Rico, a favor de una federación de las Antillas y de la reforma de una serie de males que vio en las Américas, incluyendo la abolición de la esclavitud. Su defensa de trabajadores chinos maltratados en el Perú al igual que su hostilidad hacia el proyecto ferroviario de Oruro ayudaron a modificar la opinión pública. Sus escritos ayudaron a que las mujeres en Chile accedieran a escuelas profesionales, $y$ su defensa de un ferrocarril transandino entre Argentina $y$ Chile tuvo éxito, por lo cual la primera locomotora del tramo llevaba su nombre. De 1875 a 1888 dedicó sus energías a la reforma de los sistemas educativos en la República Dominicana y en Chile.

Cuando se estableció en la República Dominicana en 1879, aprovechando el ascenso al poder de amigos liberales, se le encomendó la puesta en marcha y la dirección de la Escuela de Educación. Durante nueve años, también enseñó Derecho y escribió extensamente en la prensa, entre otras cuestiones a favor de una Confederación Antillana, que incluiría a las tres islas hispanas de Cuba, Puerto Rico y la República Dominicana. Pronto se convirtió en el "Maestro", un faro de conocimientos y la persona que introdujo el positivismo en los círculos cultos locales y el dirigente que hizo mucho para sustituir el apuntalamiento de la educación católica en la República Dominicana:

Hostos concibió la misión del intelectual en la lucha contra los deficientes legados del pasado. En el mundo del Caribe, ello implicaría la superación de formas de dependencia personal y el logro de la libre determinación. . . En su opinión, el conocimiento histórico se usaba exclusivamente para legalizar a poderes perniciosos, ya que, en nombre del progreso, se exaltaba a los déspotas. Presentó la opinión contraria que el estudio de la historia debe estar encaminado al conocimiento de las fuentes de las que la moral emerge, aquella moral arraigada en la gente común (Cassa, 1999: 395).

En 1888, Hostos se trasladó a Chile, donde su influencia se sintió igualmente en 
la formación de educadores y en el derecho, el periodismo, la literatura, con una proyección y centralidad que solo el venezolano Andrés Bello había superado. Cuando el dominio español de Puerto Rico llegó a su fin en 1898, hizo campaña por la libre determinación de Puerto Rico, fundó la Liga de Patriotas Puertorriqueños, tratando sin éxito de convencer al gobierno de los EEUu y la administración americana de la isla. Desilusionado con los resultados, regresó a Santo Domingo en 1900 y trabajó intensamente para mejorar el nivel educativo y cultural del país hasta su muerte en 1903.

El "Maestro" tenía una enorme influencia, y algunos de sus alumnos se convirtieron en historiadores pioneros a principios del siglo xx. Entre ellos se encuentra Américo Lugo, quien concibió las raíces hispanas como la fundación y la fuerza unificadora de la nación, un contrapeso de identidad en el momento de la intervención militar de los EEUU en 1916. En la misma línea que Hostos, quien vio en esas bases un "medio de oposición moral y cultural al imperialismo", Lugo fue también la figura más activa en la Unión Nacional Dominicana, el grupo que se opuso a la ocupación. De manera consecuente, presidió más tarde el partido Nacionalista. El hispanismo de Lugo tenía un fundamento popular, democrático. En la época de Trujillo, tal orientación hispanista tomaría un rumbo conservador, cuando se inserta en un enfoque centrado en el estado, según el cual "el pueblo se convirtió en una nación a través de la aparición del estado" (Cassa, 1999: 397-399).

Muchos exiliados se desarrollaron en el extranjero hasta convertirse en líderes y maduros intelectuales, académicos, investigadores o políticos, que llevan adelante proyectos de refundación de sus sociedades, a menudo obteniendo una proyección transnacional en América Latina. José Martí es un ejemplo sobresaliente de un intelectual que utilizó su capacidad literaria y oratoria a favor de una causa política, la independencia de su Cuba natal. Su capacidad pro-activa e incansable de organización, liderazgo y movilización le convirtieron en una de las figuras más influyentes en la diáspora cubana y el movimientos pro-independista de
Cuba y Puerto Rico, alcanzando asimismo una proyección transnacional.

Muy temprano en su vida, las autoridades coloniales españolas que lo habían condenado a una pena de prisión por actividades estudiantiles, conmutaron la condena por su deportación a España. Fue ese primer exilio en España en la década de los 70 del siglo XIX donde Martí recibió su educación formal, obteniendo títulos en Filosofía y Derecho en Zaragoza y Madrid. En 1874 partió de España para México, donde pudo participar activamente en la vida cultural y organizativa, el debate y la escritura, hasta que el ascenso de Porfirio Díaz al poder limitó su capacidad de activismo. Después de una breve visita a Cuba, se radicó en Guatemala, donde fue nombrado en la Facultad de la Escuela Central para enseñar Literatura Europea e Historia de la Filosofía, contribuyendo a la vida cultural. Una vez más, cambios en el poder lo obligaron a salir de Guatemala. Regresó entonces a La Habana, donde trabajó en un bufete de abogados, mientras continuaba su actividad revolucionaria en contra del dominio colonial español de la isla. Esto dio lugar en 1879 a una segunda deportación a España, aunque de allí prosiguió casi de inmediato a Francia y a continuación, a los Estados Unidos. En 1881 intentó establecerse en Caracas, pero regresó a Nueva York, donde residió con intervalos hasta su temprana muerte en 1895 (Shnookal y Muñiz, 1999: 10-13).

En los Estados Unidos, Martí se convirtió en una de las principales figuras del movimiento revolucionario cubano y puertorriqueño $y$ un intelectual ampliamente reconocido por su contribución intelectual. Escribió notas para revistas en los países de habla hispana, entre ellos en Argentina, Uruguay, Honduras y México. Trabajó como traductor. Fue designado cónsul del Uruguay en 1887, de la Argentina en 1890 y de la República Dominicana en 1892. Por encima de todo, organizó clubes patrióticos en el área de Nueva York y en Florida, donde había concentraciones de trabajadores cubanos del tabaco, a quienes entusiasmó con su prosa y discursos, plenos de energía y pasión rítmica. Pronto se convirtió, junto con los generales Máximo Gómez y Antonio Maceo — con quien 
mantuvo una relación plagada de tensión - en el espíritu vivo y la voz de quienes luchaban por la causa de la independencia de Cuba. Galvanizó y organizó a las comunidades de inmigrantes, a los residentes y los trabajadores en una serie de asociaciones de émigrés comprometidos con la causa de la liberación ${ }^{3}$. Martí también fue amigo de Ramón Emeterio Betances, considerado como el padre fundador del nacionalismo puertorriqueño, $y$ juntos organizaron clubes patrióticos, con el objetivo de lograr la independencia de ambas islas. Incluso colaboraron en un proyecto sobre una futura Confederación de las Antillas, parte de un proyecto político preventivo para evitar una futura dominación por parte de los Estados Unidos una vez que fuera lograda la independencia (Rumazo González, 1993, II: 463-465) ${ }^{4}$.

\section{IMPACTO DEL EXILIO SOBRE PREMISAS SOCIALES E INSTITUCIONALES}

La experiencia de exilio habilita $y$ a veces obliga a superar lo que a menudo fueron visiones no cuestionadas, que quienes crecen en un lugar determinado adquieren, a menudo sin tomar plena consciencia de su temporalidad $y$ carácter contextual. En este marco, contemplar los desafíos del exilio (vale decir, la potencialidad positiva de un exilio) puede ser un sesgo de corrección a la perspectiva de quienes tienden a reconocer solo pérdidas en el desplazamiento forzado.

Mientras se encuentran lejos de su país de origen, los exiliados atraviesan una serie de profundas transformaciones personales $y$ colectivas como resultado de nuevas experiencias e ideas que confrontan en el exterior y que pueden tener un fuerte impacto en su vida $y$ a menudo, también en la futura reconstrucción de las esferas públicas en la sociedad de origen.

Sobre Maceo en el exilio en Costa Rica y sus relaciones con los otros líderes del movimiento independista cubano véase Vargas Araya (2001).

En mayo de 1895 Martí desembarcó en Cuba para promover la guerra de liberación de la isla y cayó muerto en el intento.
Un caso histórico notable es el de la generación argentina de 1837 que optó por desterrarse hacia la Banda Oriental y Chile, escapando del gobierno de Juan Manuel de Rosas en el Río de la Plata. Debido al carácter transnacional de la política en las primeras etapas de la vida independiente, en el que las fronteras internacionales no constituían un obstáculo absoluto a la intervención en los países vecinos ${ }^{5}$, surgió una situación en que se afirmaba la posibilidad de usar a los exiliados para desarrollar al país y tal vez avanzar los intereses y reivindicaciones territoriales del país de acogida. Por ejemplo, estando en el exilio en Chile, Juan Domingo Sarmiento - años más tarde presidente de la Argentina - apoyó la reivindicación de la soberanía chilena sobre el Estrecho de Magallanes, como parte de su antagonismo a Rosas. Según el historiador chileno Francisco Encina, este tipo de preocupaciones transnacionales probablemente influyó en las decisiones de los políticos chilenos acerca de la acogida de los exiliados de los países vecinos en el periodo que va de 1843 a 1879 (Encina, 1947, 7: 605).

Una vez en Chile, los exiliados del Río de la Plata, en su mayoría de antecedentes e ideas liberales, se convirtieron rápidamente en acólitos vinculados a la elite gobernante chilena, alabando sus políticas estatales de consolidación institucional. Los exiliados conocieron elites gobernantes modernizantes, cuyo proyecto de consolidación institucional les atrajo a pesar del carácter conservador que denotaba en el plano económico y la perspectiva autoritaria que lo sustentaba en el plano social y político. Al ubicarse en los estadios medios de la esfera pública de Chile, los exiliados rioplatenses se vieron impulsados a modificar su visión originaria, producto de la oposición al régimen de Rosas ${ }^{6}$.

5 Véase Chiaramonte (1997) para el cono Sur, Holden (2006) para América Central y Demélas (2003) para los países andinos.

6 Además, los desterrados intentaban mostrar que la mala imagen que Rosas y sus propagandistas querían difundir acerca de ellos era una fabricación sin asidero en la realidad, ya que ellos no perturbaban el orden público en Chile, a diferencia de la mala imagen que el gobernante de Buenos Aires intentaba propagar. 
Los jóvenes militantes argentinos encontraron en Chile lo que a sus ojos era un admirable modelo de autoritarismo constitucional. Este sistema, apoyado por las élites socio-económicas, parecía trabajar en favor de las reformas civiles, el mejoramiento moral de las masas y el progreso material de la nación chilena, objetivos que antes del destierro ellos habían identificado con el liberalismo, mientras en Chile los liberales chilenos no planteaban una alternativa realista al modelo conservador creado por Diego Portales. Es así que los exiliados rioplatenses adaptaron la mentalidad jerárquica del modelo chileno. Los exiliados desarrollaron así un bagaje ideológico eminentemente conservador en el plano social, con valores que se convertirían en la base de la transformación liberal de la Argentina después de la caída de Rosas.

Sus principios e ideales proyectaron la marca de un liberalismo conservador que iría a dominar la Argentina hasta bien entrado el próximo siglo. Cuando Julio Argentino Roca llegó al poder en 1880, Juan Bautista Alberdi, Domingo Faustino Sarmiento, Bartolomé Mitre y Vicente López - todos los cuales habían regresado del exilio en Chile- habían logrado un consenso acerca de los temas más importantes de Argentina. No veían un problema en que la dirección de su sociedad estuviera firmemente en manos de una pequeña élite, cuyas ideas políticas y sociales conservadoras en general coincidían con la visión que adoptaron en Chile. William Katra llega a la conclusión de que, mientras que antes sus críticas estaban dirigidas al sistema cerrado del localismo perpetuado por los caudillos, ahora podrían aplaudir un liberalismo que proyectaba una visión social conservadora (Katra, 1996: 86, 300).

El enfrentamiento con nuevas realidades $y$ desafíos provocó nuevos planteamientos relativos a cuestiones de identidad, no sólo a nivel personal, sino elaboraciones conducentes a la reformulación de los principios colectivos de la vida en sociedad. Se analizaron los problemas de la construcción de la nación y las posibles vías de desarrollo de las naciones y estados, en términos de la distancia y la posible combinación entre lo primordial y lo construido por la política, ambos elementos que pueden ser incorporados en el estado-nación o ampliados a una fraternidad latinoamericana, a partir de las experiencias compartidas.

La ampliación de horizontes ha sido la casi natural consecuencia del destierro. José Carlos Mariátegui, una de las principales figuras del pensamiento peruano e iberoamericano en el siglo xx, lo expresó en forma clara al indicar que los años que pasó en el extranjero fueron instrumentales "no para buscar los secretos de los demás, sino en la búsqueda de nuestro propio secreto". José Luis Rénique, que estudió la vida y obra de Mariátegui, ha sugerido que la trasladación al extranjero le sirvió a Mariátegui así como a muchos otros para superar las ideas prestadas y limitantes de la modernidad y alcanzar una visión más amplia, en su caso una visión de la humanidad que reconciliase lo universal con su particular comprensión de la sociedad peruana $y$ andina (Mariátegui, 1994; Rénique, 2006; Racine, 2000: xi-xx).

\section{TRANSFORMACIONES PROFUNDAS Y PARCIALES}

El exilio es una experiencia traumática de violación de los derechos humanos que plantea retos personales y colectivos ${ }^{7}$. El destierro impulsa nuevas experiencias, genera nuevas ideas $y$ permite comprender desde nuevos ángulos la política y las funciones sociales, incluyendo los roles de pareja, género y familia. A menudo los residentes en el exilio problematizan y amplían sus perspectivas de identidad $y$ desarrollo personal así como su entendimiento de la relación entre lo nacional, lo transnacional y lo universal.

El destierro genera inseguridad financiera y psicológica; puede desplomar la confianza; demanda nuevos modos de interactuar; desarticula las relaciones personales en virtud de las presiones vitales, como lo demuestra la tasa general de divorcio empinadas en las comunidades del exilio en la última ola represiva. Para muchos, además, puede ser difícil encontrar una nueva dirección o un nuevo propósito en la vida (Barudy, et ál. 1980; Grinberg y Grinberg, 1984, Vásquez y Araujo, 1988). 
Esto a menudo fuerza a reconsiderar verdades que se consideraban evidentes. En el marco de los estados-nación, el exilio agudiza y revela una tensión que subyace en forma permanente, la tensión entre el principio de pertenencia a una nación y el principio de ciudadanía. Ambos principios se confunden en el marco de los estados-nación, indisolublemente combinados bajo la lógica operativa del Estado $y$ la socialización escolar. Pero, una vez que una persona es desterrada - o sea, expulsada del territorio nacional, o empujada a migrar por temor a verse afectada en su integridad física o por haber elegido el exilio para escapar de la falta de libertad- se produce una ruptura entre el principio de ciudadanía sostenido por el Estado y el proyecto de nación que los exiliados han imaginado poder construir y compartir. Se disocian así los principios de nacionalidad y ciudadanía y se abre un ambiguo proceso de transformación personal y colectiva que la historia $y$ las ciencias sociales aun deben develar en toda su complejidad (Roniger y Yankelevich, 2009; Sznajder $y$ Roniger, 2009). En diversos testimonios y obras de investigación y reflexión sobre el exilio ${ }^{8}$ encontramos referencias a este proceso de transformación, pleno de tensiones, que a menudo se manifiesta como una lucha entre el espíritu no doblegado de resistencia $y$ la necesaria aclimatación al nuevo lugar de residencia o asilo.

En este proceso, podemos identificar una variedad de vías de transformación, que van desde personas que se aferran a sus diferentes visiones localizadas y conceptos de identidad, hasta llegar a quienes adoptan visiones complejas, incluyendo una visión más transnacional o incluso mundial.

Más allá de tales diferencias, existe una tendencia casi universal a reconsiderar lo que salió mal en el país de origen en términos que van más allá de explicaciones circunstanciales. De la experiencia que lo llevó al exilio, Domingo Faustino Sarmiento, que luego sería presidente de la Argentina, dedujo del exilio de la Generación de 1837 el valor de la tolerancia

Un análisis de los avances teóricos en los estudios sobre exilio va más allá de los objetivos de este trabajo, siendo elaborado en otro lugar (Roniger, 2009). y la necesidad de generar un debate abierto, donde diferentes puntos de vista y esferas públicas plurales pudieran florecer.

Igualmente, después de dos años en el exilio, el historiador y político guatemalteco Manuel Montúfar y Coronado aconsejaba la tolerancia a sus co-nacionales en un tratado de análisis histórico publicado en 1832. En aquel trabajo, Montúfar y Coronado proponía al gobierno de Centroamérica, dominado entonces por los liberales, la convergencia de partidos en torno a intereses compartidos, en lugar del revanchismo que podrían abrigar quienes habían sido proscriptos de la dirección de la república. Hacia el final de su detallado análisis de la situación centroamericana, Montúfar preguntaba retóricamente:

¿Sería un remedio llamar a los proscriptos y confiarles la dirección de los negocios? Tampoco bastaría esta medida: no sería otra cosa que el turno de un partido caído que se levanta para volver a caer: ninguna administración confiada exclusivamente a uno de los partidos puede ser nacional, ni dejaría de ser vengativa y perseguidora: individualmente se encontrarían sentimientos justos, equitativos y generosos; pero la masa abrigaría un sentimiento exclusivo, $y$ los sentimientos exclusivos no pueden ser nacionales ni producir la paz y el orden por más que se busquen.

... Para sostenerse los que dominan actualmente aquella república, necesitan reformar sus leyes, fundir los partidos, ser verdaderamente tolerantes, $y$ no pretender que sea eterno lo que en ningún país ha podido ser duradero; esto es, un partido que bajo formas democráticas quiera gobernar exclusivamente una nación en que hay opiniones e intereses diversos (Montúfar, 1934: 250-253, c. 1832).

De manera similar, la experiencia de Vicuña Mackenna al verse forzado a ir al exilio lo llevó a indagar el análisis histórico del desarrollo de su país natal. Según Vicuña Mackenna, 
ya habían tenido lugar dos revoluciones en Chile, la conservadora de 1829 que colocó a Portales a la cabeza de la República, y una revolución liberal, también problemática. En sus estudios durante el exilio, llegó a la conclusión de que ambas revoluciones habían alcanzado sólo resultados parciales debido a la violencia que generaron en el pasado. Una tercera revolución, la revolución del futuro, debería ser consumada sin derramamiento de sangre en batallas $y$ sin someter a voces discordantes a las cuerdas del cadalso, sin las cadenas de la prisión o las listas de personas proscriptas. La revolución del futuro debería ser una revolución en paz; de mentes trabajadoras y fructíferas; de fe y de amor; de espíritu y conciencia; de ideas que en un día no lejano llevarían a cabo la regeneración de la humanidad (Vicuña Mackenna, 1936, vol. 2: 386, en Rénique, 2006). Para lograr tal objetivo ideal, Vicuña Mackenna se dedicó a escribir la historia de Chile en clave de justicia histórica, examinando el daño causado por el ostracismo y resaltando la necesidad de la reconciliación. Produjo docenas de libros, entre ellos dos sobre los más prominentes exiliados, los hermanos Carrera y el General Bernardo O'Higgins, héroes de la guerra de independencia que fueron enemigos en vida, aunque ambos terminaron sus vidas en el exilio (Vicuña Mackenna, 1857, 1860).

Al escribir la historia sobre los Carrera y sobre O'Higgins, así como sobre Portales, cuyos seguidores habían provocado su propio exilio, Vicuña Mackenna se proponía expresamente transformar la esfera política a través de un aporte al entendimiento sobre la importancia de la reconciliación nacional y una mayor apertura del juego político. A través de su escritura de la historia, este intelectual elaboró un proyecto historiográfico encaminado a la reintegración de los que habían sido excluidos en el pasado dentro de la memoria colectiva, a fin de conciliar el liberalismo con el autoritarismo del modelo conservador de Portales. En su visión, aun cuando el estado ideado por Portales había permitido una excepcional estabilidad institucional en Chile, debería ser reorientado hacia la formación de una República más inclusiva. Al escribir sobre los dirigentes del pasado próximo, Vicuña
Mackenna trató de mostrar los peligros de la confrontación y la violencia interna, $y$ propuso un modelo de desarrollo chileno de significado universal. Según su visión, el faccionalismo y la violencia política conducentes al ostracismo $y$ al destierro eran el principal obstáculo para el desarrollo. En contraste, el desarrollo debería basarse en el diálogo político civilizado, haciendo espacio para la construcción de una política estable y próspera. Esta imagen está estrechamente vinculada a las ideas liberales y positivistas, $y$ sería integrada en la modernización de Chile en la segunda mitad del siglo XIX9.

El exilio constituye un cruce de caminos de los procesos de importancia fundamental para repensar la política y para la renovación de la política. El exilio ofrece oportunidades de aprendizaje para los actores políticos obligados a vivir y conocer otras agendas políticas y proyectos que desconocían. El siglo XX ofrece numerosos ejemplos de tal aprendizaje, que no podemos analizar aquí detalladamente por razones de espacio. Meramente ilustrativo es el caso de Germán Bosch, de la República Dominicana. Sus 26 años en el exilio, vividos a partir de 1935, fueron un período de aprendizaje político y de transformación ideológica hacia el fortalecimiento democrático. En cuanto regresó a la República Dominicana en 1961 intentó aplicar estas ideas en su país de origen $y$ fue electo a la presidencia en febrero de 1963:

Durante sus siete meses en el cargo Bosch trató de establecer un modelo de gobierno democrático. Alentó la organización amplia de los movimientos obreros y campesinos, patrocinó la aprobación de una ley de reforma agraria, $y$ financió un amplio programa para la formación de líderes de cooperativas locales, sindicatos y municipios. El gobierno de Bosch también mantuvo el pleno ejercicio de las libertades civiles (http://www.bookrags. com/biography-juan-bosch/index.html [22 de junio de 2006]).

9 Vicuña Mackenna fue alcalde de Santiago en 187275 y junto con otros miembros de la llamada generación de 1842, muchos de los cuales habían sufrido el exilio, desempeñó un papel importante en el proceso de modernización. 
Una generación más tarde, en el punto más álgido de la Guerra Fría, los exiliados de la izquierda latinoamericana que encontraron asilo en los países comunistas, incluyendo Cuba, experimentaron de cerca el "socialismo real", viéndose impulsados a reafirmar o - en muchos casos - a re-evaluar la viabilidad de sus posiciones ideológicas previas (vg. Rodríguez Elizondo, 1996; Prestes Massena, 2007).

Las experiencias del exilio en los estados liberales occidentales llevaron a una mejor comprensión de las prácticas democráticas, la sociedad civil y el estado de bienestar social, que en Europa por ejemplo eran articuladas de manera diferente a lo acostumbrado en los países de origen. La esfera pública internacional, más consciente de las violaciones de los derechos humanos en América Latina, también permitió la acción política de redes nacionales $y$ transnacionales que ayudaron a propulsar las transiciones democráticas, facilitando en muchos casos el apoyo material $y$ discursivo de quienes luchaban contra los gobernantes autoritarios. Además, el proceso de transformación del régimen autoritario en el sur de Europa, en particular en España, hizo fuerte impresión sobre los exiliados, especialmente al ser testigos de primera mano del proceso acelerado de apertura democrática. Paralelamente, estas experiencias desencadenaron un proceso de reevaluación de los procesos políticos que habían conducido a las crisis institucionales que llevaron a su propio exilio (Angell, 1996; Barahona de Brito, 1997; Roniger y Sznajder, 1999).

La combinación de introspección y conocimiento de primera mano de procesos más amplios de transformación sirvió de base para una nueva generación de activistas políticos para quienes el exilio fue un factor catalizador en la reconfiguración de los credos políticos. En casos como los de Chile y Brasil, con dictaduras de larga proyección (1973-1990 y 1964-1985, respectivamente), la experiencia conjunta de los desplazamientos en masa de las elites políticas y la transformación de la escena mundial condujo a los partidos políticos hacia el centro del espectro político, junto con el abandono parcial o total de los ideales revolucionarios y la retórica radical de la extrema izquierda:

La experiencia del terrorismo de Estado era la principal experiencia de aprendizaje que guiaba el cambio. Como lo expresó José M. Insunza: 'antes del golpe, nos daba menos importancia la democracia porque no habíamos tenido la experiencia de la dictadura y las violaciones de los derechos humanos habían sido esporádicas. La democracia representativa $y$ el socialismo se integran en nuestro discurso, [mientras que] en el viejo discurso eran términos antagónicos'. (...) La renovación tuvo lugar tanto en la patria como en el extranjero, pero la corriente renovadora era más fuerte entre los exiliados, en particular los de Europa. Los exiliados citaban una serie de experiencias que les había empujado hacia la renovación. Jorge Arrate, un líder en el movimiento de renovación, hizo hincapié en que la exposición de primera mano a los acontecimientos internacionales y las corrientes intelectuales fue decisiva. Los exiliados fueron influenciados por Gramsci, los debates sobre el Euro-comunismo y la Perestroika, el desarrollo del movimiento obrero polaco Solidaridad y su represión, la invasión soviética de Afganistán. . . Muchos chilenos estaban particularmente impresionados por la labor de Felipe González y el Partido Socialista español en la era post-franquista. [Al mismo tiempo,] los exiliados en Europa occidental y otros muchos países de acogida fueron capaces de discutir, conocer y difundir libremente sus ideas-oportunidades inexistentes en Chile hasta la pequeña apertura de 1984 (Wright y Oñate, 2007: 42-43).

En efecto, el impacto fue recíproco. En un reciente trabajo, Maria Rosaria Stabili llega a la conclusión que el exilio de algunos dirigentes de la Unidad Popular, la coalición gubernamental de Salvador Allende, en Italia durante los primeros años de la dictadura de 
Pinochet, contribuyó a la elaboración de nuevos enfoques políticos tanto para Chile como para Italia. Stabili destaca que los eventos en Chile influyeron crucialmente sobre Enrico Berlinguer, líder del Partido Comunista Italiano (PCI), que comenzó a promover la idea de lo que se conoce como la Compromesso Storico entre los principales partidos políticos. Este "compromiso histórico" preveía lanzar junto con la Democracia Cristiana encabezada por Aldo Moro una estrategia de coalición conducente a un gobierno de unidad democrática ${ }^{10}$. En forma paralela, los líderes exiliados de Chile en Italia contemplaron la propuesta de una alianza de todos los partidos democráticos para derrotar a Pinochet. Esta propuesta fue elaborada en una conferencia en Ariccia, cerca de Roma, en 1979. En esa reunión, los dirigentes políticos chilenos exiliados en los diferentes países produjeron la génesis de la Concertación para la Democracia, una coalición de 17 partidos que lograría derrotar a Pinochet en el referéndum de octubre de 1988 que denegó al General la posibilidad de seguirse manteniendo en el poder por largos años, iniciando la transición a la democracia (Stabili, 2009).

De manera similar, en un análisis de las diferentes experiencias de los diversos partidos políticos chilenos en el exilio, Alan Angell destaca el proceso de una doble transformación: un debate sobre las lecciones de la experiencia chilena que dio lugar - al menos en Europa occidental - a un replanteamiento de las estrategias políticas de la izquierda, y una transformación de la forma de pensar de los exiliados, que fueron profundamente afectados por el debate político que se desarrolló en el contexto europeo:

El debate sobre el euro-comunismo ayudó a producir una Izquierda chilena más moderada y pragmática. La izquierda europea estaba desarrollando ideas sobre la conveniencia de la economía mixta y la necesidad de cooperación

Esta estrategia trágicamente llegó a su fin en 1979 con el secuestro y ejecución de Aldo Moro por las Brigadas Rojas. entre el capital, la clase trabajadora y el gobierno, un debate que afectaría profundamente a los chilenos exiliados, especialmente a los de los partidos socialistas. Los chilenos exiliados en Venezuela también parecen haber sido persuadidos de las virtudes del entendimiento político como instrumento para la consolidación de una democracia estable. Los exiliados que se establecieron en los países que destacaban la revolución en lugar de la democracia — tales como México, Cuba o Nicaragua- parecen haber mantenido sus creencias en la corrección esencial de los objetivos del gobierno de la Unidad Popular de una forma más firme (Angell, 1996: 180).

El partido chileno más afectado por el exilio y la represión fue el Partido Socialista. De hecho, cuando los socialistas exiliados comenzaron a regresar a Chile a mediados de los años 80 , aportaron sus experiencias conceptuales $y$ organizativas $y$ tuvieron fuerte influencia en la renovación del Partido Socialista dentro de Chile. Sin abandonar un compromiso con la cuestión social, los dirigentes y activistas -entre ellos muchos influenciados por su experiencia y el aprendizaje operados en el exilio- condujeron a la reconfiguración de la izquierda en términos pragmáticos, apoyando los nuevos modelos de economía de mercado y el pluralismo político (Wright y Oñate, 2007).

Basándose en la experiencia de los repatriados brasileros, Denise Rollemberg complementa lo anterior, evaluando el profundo efecto transformador del exilio sobre la política $y$ los proyectos de vida de muchos brasileños en un sentido que abarca tanto los valores cotidianos como conceptos políticos:

La manera de luchar con lo cotidiano fue reevaluada. Los valores cambiaron. Las mujeres reconsideraron su rol social, cuestionando el machismo y la opresión tradicional. De una cultura política básicamente autoritaria, se transitó a una valorización — por cierto muy desigualde la democracia. El Brasil pasó a ser visto de afuera. Las fronteras nacionales 
estrechas se ampliaron. El provincianismo cedió lugar al cosmopolitanismo. Los exiliados que, al principio, ostentaban tan orgullosamente tal condición, pasaron a aceptar el [rótulo] de refugiado. El tiempo pasó... La diversidad y la intensidad de las experiencias produjeron transformaciones imprevistas... Los conceptos tradicionales de revolución fueron repensados y otro asunto vino a ocupar el centro del palco: la democracia. Entre raíces y radares, los exiliados reevaluaron el proyecto que había sido vencido, abandonaron algunos de sus aspectos centrales, agregaron otros, reconstruyeron caminos y concepciones de mundo, redefiniéndose a sí mismos, entre lo que dejaban atrás y lo que percibían delante de ellos: las contradicciones, las tradiciones del pasado y las novedades del presente [frente al] futuro (Rollemberg, 1999: 302).

Entre los políticos y los intelectuales en el exilio, hubo cuestionamientos e indagaciones: se comparó la experiencia en el exilio con la visión ideológica y utópica, imágenes que habían alimentado sus estrategias de acción. Por necesidad, se inició una reevaluación de proyectos, sueños y ambiciones.

Debemos tener presente, empero, que no se trata de una transformación generalizada, sino más bien de complejos cambios de posiciones y puntos de vista que se dan de una forma progresiva y que se ligan en forma parcial con anteriores visiones y proyectos de vida. Un estudio sobre la última ola de uruguayos exiliados realizado por Vania Markarian destaca la complejidad y multiplicidad de la transformación. Según la autora, la participación en las redes de derechos humanos durante la dictadura en Uruguay "hacía necesaria una revisión del discurso heroico tradicional de la izquierda que planteaba la represión y los abusos como parte de la experiencia política esperada ['normal'] y eludía referencias y denuncias legales con el fin de subrayar las reivindicaciones sociales $y$ económicas" (Markarian, 2005: 7). Una vez en el destierro, los exiliados de la izquierda uru- guaya no sustituyeron totalmente su visión del mundo. Por el contrario, la mayoría mantuvo líneas ideológicas previas y sin embargo, la experiencia en el extranjero y la percepción de los cambios en la política mundial y nacional en la década de los 70 del siglo xx los llevó a participar activamente en la red transnacional de los derechos humanos para denunciar la represión del gobierno de su patria. Su propio éxito en sensibilizar a la opinión pública internacional respecto de las violaciones de los derechos humanos los tomó por sorpresa, al igual que tal transformación en la centralidad del discurso global tomó por sorpresa igualmente a los gobiernos represores. Ello llevó a que los exiliados interpretaran el aislamiento creciente del régimen uruguayo no como el resultado de un cambio en la política de los EEUU o las políticas de la OEA, sino más bien como el resultado de su propio activismo político. En verdad, la presión de los exiliados fue un factor importante en este desarrollo, pero en sus círculos internos se siguió usando la retórica de la revolución, en aparente tensión con su discurso 'externo' de protección de los derechos humanos, siendo este usado para convencer a los abogados europeos y los congresistas norteamericanos a que cooperaran en promover la condena del gobierno autoritario en el país natal (Markarian, 2005).

Entre los múltiples ámbitos afectados se destaca el capital humano, el desarrollo de capacidades y la conciencia de que pueden transferirse en el más amplio ámbito espacial. La experiencia del exilio de la década del 70 y del 80 hizo posible una capitalización cultural con claras implicaciones, gracias a los países receptores y la calidad humana de los desterrados y migrantes. El exilio permitió un mejor acceso a bienes y recursos que en la patria, produjo una ruptura con lazos heredados; realzó la importancia del trabajo; demostró que la subordinación no sólo afecta a los países del tercer mundo; amplió la red de seguridad social; rehizo concepciones de género y lazos de pareja; incrementó la independencia de los hijos respecto de los padres; redujo la presión social; permitió desarrollar la solidaridad hacia personas diferentes; difundió imágenes y estilos 
latinoamericanos por todo el mundo; facilitó el acceso de los desterrados a talleres de capacitación; $y$ en general, permitió una fructífera confrontación con los propios estereotipos y prejuicios (Díaz y Wettstein, 1989; Benedetti, 1997: 19-21). Especialmente importante a finales de siglo xx fue el cambio experimentado por muchas mujeres que huyeron de sus países de origen y una vez en el extranjero, adoptaron nuevas visiones de género, pareja $y$ maternidad que interpelaron las visiones proyectadas desde el país de origen, aun por quienes se declaraban revolucionarios (Véase por ejemplo Vásquez y Araujo, 1988: 129-162; Kay, 1989; Freyre, 1995; Pessar, 2001; Sznajder y Roniger, 2009: 293298). Podemos concluir afirmando que la experiencia del exilio ha marcado la vida de muchos con un efecto duradero en el ámbito de las actitudes, las normas y prácticas de comportamiento, a menudo proyectadas — no sin tensiones y ambigüedades - a los países de origen.

Si bien los exiliados comparten el proceso de desplazamiento con otros viajeros, migrantes y residentes, su reubicación en el extranjero está estrechamente relacionada con una profunda $y$ persistente preocupación por entender los procesos pasados y los eventos que se despliegan en la sociedad de origen. A menudo, se verán inmersos en un diagnóstico $y$ evaluación persistente acerca de los factores que impidieron el logro de su proyecto político, surgirán dudas acerca de la visión colectiva que ellos sustentaron hasta entonces, y en no pocos casos, ello llevará a una redefinición del horizonte colectivo, de las visiones de mundo y de las estrategias orientadas a producir cambios políticos e institucionales en el país de origen. Los exiliados atraviesan esa serie de profundas transformaciones personales y colectivas de forma ineludible.

\section{CONCLUSIONES}

A menudo, el exilio permitió la transformación de identidades y tornó las visiones de mundo en unas más reflexivas. Analizando la obra de los escritores iberoamericanos exiliados en la última ola de autoritarismo, la crítica literaria Florinda Goldberg ha estimado que la experiencia del exilio ha interpelado tanto las visiones nacionales como las transnacionales:

El "provincialismo" nacional se sustituye por una visión global de América Latina en su conjunto, lograda al vivir en otro país del continente, o en cualquier otro lugar con otros expatriados del continente. [Tununa] Mercado dice que, después de sus logros intelectuales en Francia, 'en México me di cuenta de la diferencia [entre los países de América Latina]: la cultura prehispánica, el arte moderno, las diferentes literaturas del país, pero sobre todo la educación de la gente, cómo utilizan su español, cómo se mueven'. 'Aprendimos que no somos el ombligo del mundo', dice Achúgar. [Noé] Jitrik habla de superar la falacia 'ofmalocéntrica'. . . [Para muchos exiliados de visión crítica,] ir al exilio fue ampliar las perspectivas que hasta entonces se habían circunscrito casi exclusivamente a las nacionales (Goldberg, 2002: 303).

La experiencia de exilio ha abierto oportunidades imprevistas que permiten adquirir nuevas habilidades, aprender idiomas, descubrir fortalezas y reconocer debilidades, desarrollar nuevas relaciones y comprender desde nuevos ángulos las funciones sociales, incluyendo los roles de género. Este trabajo ha indicado como en el extranjero, parte de los ciudadanos desplazados de un territorio nacional han cambiado sus perspectivas políticas, sociales y culturales, adoptando nuevas perspectivas a través de sus experiencias en el destierro. A menudo, el destierro ha permitido asimismo una ampliación de perspectivas sobre identidades personales, nacionales e iberoamericanas en un plano transnacional.

Hemos analizado aquí casos salientes de exiliados que tuvieron un impacto importante en la cristalización de visiones colectivas y la redefinición de compromisos políticos, impactando los países de origen de formas diversas. El pasaje de las visiones elaboradas en el exilio hacia los países de origen no es un proceso simple o universal. A menudo, el retorno del exiliado da lugar a nuevos ajustes sólo parcialmente 
anticipados, convirtiéndose en muchos casos en un nuevo exilio. El país ha cambiado con el paso de los años, $y$ los exiliados pudieron seguir sólo parcialmente dichas transformaciones, sobre todo cuando una dictadura se ha prolongado en el poder, descartando la posibilidad de un pronto regreso.

Cuando los exiliados han mantenido una sintonización política, social y cultural con el país de origen, esta conexión puede facilitar la decisión de regresar. Sin embargo, las conexiones y vínculos con co-nacionales sólo puede facilitar y no anular las dificultades de reinserción de regreso a la patria. En un reciente libro, José Luis Abellán identifica tres modos de «desgarro», tres sentidos de estar desgarrado/a por el desplazamiento forzado. Abellán sugiere distinguir entre refugiados, desterrados y exiliados. Los refugiados adoptan una lógica de la supervivencia, al intentar acomodarse al país de acogida. Los desterrados se adaptan al nuevo entorno en términos de lo que han dejado atrás. En la tercera modalidad — representada según Abellán por la escritora y filósofa María Zambrano- las personas se mueven a una posición más radical, donde perciben que tras el exilio, la vida errante se ha tornado en el destino final del exiliado. Bajo tal perspectiva, el final del ostracismo y el retorno al país de origen no curan las heridas. De hecho, el exilio puede llegar formalmente a su fin $y$ sin embargo, para las personas repatriadas, el exilio no tiene fin, es un estado en el cual uno se siente completamente huérfano, después de haber perdido para siempre un lugar en el mundo que fuera otrora concebido como un lugar natural y que, luego del destierro, se torna en un lugar más, ya cuestionable bajo perspectivas más híbridas y diversificadas de vida (Abellán, 2001: 45-57).

En cierto sentido, el problema del re-encuentro es que, al haber cambiado en paralelo, tanto los exiliados como quienes permanecieron en la tierra natal a menudo se convierten en extraños el uno para el otro. El crítico literario Hugo Achúgar, después de haber sufrido un exilio de su Uruguay natal, reflexiona sobre esta doble dinámica de alejamiento y reencuentro con los co-nacionales, destacando que el retorno agudiza las dificultades del des-exilio:
Uruguayos del exilio y del desexilio... somos seres entre dos aguas, marginales de ayer $y$ de mañana... extranjeros... tanto en el exilio como al regresar... Volver fue, de algún modo, comprobar lo obvio: "la imposibilidad de retornar al hogar" como dice Thomas Wolfe... El lugar mítico era real en su potencialidad, una vez lograda la concreción se convierte en el lugar del encuentro y del desencuentro. La foto está movida...Vueltos al hogar 0 al menos con la ilusión de haber vuelto realmente al hogar luego del retiro... nos encontramos con todo y con todos cambiados: nosotros los idos, en primer lugar. Recuperábamos el país y perdíamos el país. Si lo provisorio fue signo de parte del exilio lo que nos tocaba vivir ahora a la vuelta era también lábil, inseguro, transitorio, estamos en proceso de desexilio ya que el desexilio no se da de una vez y para siempre. El desexilio no es una estruendosa y única representación, no es un acto único y definitivo. Es una herida larga que puede o no, curarse (Achúgar, 1987: 242-243; Goldberg, 2000: 299-300) ${ }^{11}$.

Desde el primer momento, el exilio se basa en un acto de exclusión institucionalizada fundada en la interacción entre el país expulsor y los exiliados que fueron privados de sus derechos de ciudadanía y de toda posibilidad de participación en la esfera pública nacional, proyectándose hacia la esfera de otros estados y el ámbito transnacional. Una vez en el extranjero, el país anfitrión, $y$ a menudo la esfera pública internacional empiezan a jugar roles de creciente importancia en la ecuación del exilio. En tal esquema, el retorno supone una inversión de la exclusión del país de origen y una inclusión en el nuevo país de acogida. Sin embargo, los caminos del post-exilio son variados y no existe una correlación simple entre la vía del exilio y el retorno. Su estudio sistemático es uno de los

Las dificultades de los exiliados de clase popular son aun mayores, véase Celedón y Opazo (1987: 41-57). 
desafíos abiertos a futuros estudios de este fenómeno de tanta trascendencia política y cultural como es el exilio iberoamericano.

\section{BIBLIOGRAFÍA CITADA}

Abellán, José Luis. El exilio como constante y como categoría. Madrid. Editorial Biblioteca Nueva, 2001:45-57.

Achúgar, Hugo. "Entre dos orillas, los puentes necesarios". Saúl Sosnowski (comp.) Represión, exilio y democracia: La cultura uruguaya. College Park y Montevideo. University of Maryland $y$ Ediciones de la Banda Oriental, 1987:242-243.

Angell, Alan. "International Support for the Chilean Opposition, 1973-1989: Political Parties and the Role of Exiles". Laurence Whitehead (comp.). The International Dimensions of Democratization. Europe and the Americas. Oxford: Oxford University Press, 1996.

Ardao, Arturo. Génesis de la idea y el nombre de América Latina. Caracas: Centro de Estudios Latinoamericanos Rómulo Gallegos, Consejo Nacional de la Cultura, 1980.

Arrate, Jorge. "Exilio". Textos de denuncia y esperanza. Santiago: Documentas, 1987.

Barahona de Brito, Alexandra. Human Rights and Democratization in Latin America. Uruguay and Chile. Oxford: Oxford University Press, 1997.

Barudy, J. et ál. Así buscamos rehacernos. Represión, exilio y trabajo psicosocial. Santiago: COLAT-CELADEC, 1980.

Benedetti, Mario. Andamios. Madrid: Editorial Alfaguarda, 1997.
Brading, David. The First America. Cambridge: Cambridge University Press, 1993.

Cassa, Roberto. "Historiography of the Dominican Republic". In: B. W. Higman. "Methodology and Historiography of the Caribbean". General History of the Caribbean VI. London y Oxford: Unesco Publishing y Macmillan, 1999.

Celedón, María Angélica y Opazo, Luz María. Volver a empezar. Santiago: Pehuén, 1987.

Chiaramonte, Juan Carlos. Ciudades, provincias y estados. Orígenes de la nación Argentina, 1800-46. Buenos Aires: Ariel, 1997.

Clavijero, Francisco Javier. Capítulos de Historia y Disertaciones. Mexico: Imprenta Universitaria, 1943.

Demélas, Marie-Danielle. La invención política. Bolivia, Ecuador y Perú en el siglo $X I X$. Lima: IFEA e Instituto de Estudios Peruanos, 2003.

Díaz, José Pedro y Germán, Wettstein. ExilioInxilio. Dos Enfoques. Montevideo: Instituto Testimonios de las Comarcas y del Mundo, 1989.

Dutrénit Bielous, Silvia; Allier Montaño, Eugenia y Coraza de los Santos, Enrique. Tiempos de exilios. Memoria e historia de españoles y uruguayos. Colonia Suiza, Uruguay: CeAlCI-Fundación Carolina e Instituto Mora, 2008.

Dym, Jordana. From Sovereign Villages to National States. City, State and Federation in Central America, 1759. 1839. Albuquerque: University of New Mexico Press, 2006.

Encina, Francisco Antonio. Historia de Chile. Santiago de Chile: Editorial Nacimiento, 1947. 
Franco, Marina. Exilio. Argentinos en Francia durante la dictadura. Buenos Aires: Siglo XXI, 2007.

Freyre, Marlinda. "The Latin American Exile Experience from a Gender Perspective: A Psycho-Dynamic Assessment”. Refuge 14. 1995: 14-25.

Gerbi, Antonello. O novo mundo. História de uma polémica (1750-1900). Sao Paulo: Companhia das Letras, 1996.

Giménez López, Enrique (Comp.). Expulsión y exilio de los Jesuitas españoles. Alicante: Universidad de Alicante, 1997.

Goldberg, Florinda. "Latin American Migrant Writers: Nomadic, Decentered, Contrapuntal". En: Roniger, Luis y Waisman, Carlos H. Globality and Multiple Modernities. Brighton. Sussex Academic Press, 2002: 299-300.

Grinberg, Luis y Grinberg, Rebeca. Psicoanálisis de la migración y del exilio. Madrid: Alianza Editorial, 1984.

Halperin Donghi, Tulio. Proyecto y construcción de una nación. Caracas: Biblioteca Ayacucho, 1980.

Heredia Vargas, Raimundo. "El retorno: Una perspectiva de los que volvieron desde Suecia”. Documento de trabajo 40. Universidad de Chile: Instituto de Ciencia Política, 1994.

Holden, Robert H. Armies without Nations: Public Violence And State Formation In Central America, 1821-1960. Oxford: Oxford University Press, 2006.

Hollis, Christopher. The Jesuits. A History. New York: Macmillan, 1968.

Hostos y Bonilla, Eugenio María de. "18391903 Biography”. 2006. En: <http://www. loc.gov/rr/hispanic/1898/hostos.html> [Consultado: 13 de junio de 2006].

Jaksic, Ivan. "Sarmiento and the Chilean Press, 1841-1851". Halperin Donghi, Tulio; Jaksic, Ivan; Kirkpatrick, Gwen y Masiello, Francine (comps.). Sarmiento: Author of a Nation. Berkeley: University of California Press, 1994.

Jensen, Silvina. La provincia flotante. El exilio argentino en Cataluña (1976-2006). Barcelona: Casa de América Cataluña, 2007.

Jensen, Silvina. "Representaciones del exilio y de los exiliados en la historia argentina". Estudios Interdisciplinarios de América Latina y el Caribe 19 (2). 2009: 19-40.

Kay, Diana. "The Politics of Gender in Exile: Chileans in Glasgow". Joly, Danièle y Cohen, Robin (comps.). Reluctant Hosts. Aldershot. Averbury, 1989: 104-124.

Katra, William H. The Argentine Generation of 1837. London: Associated University Press, 1996.

Mariátegui, José Carlos. "Siete ensayos de interpretación de la realidad peruana". Mariátegui Total. Tomo I. Lima. Empresa Editora Amauta, 1994: 6-157.

Markarian, Vania. Left in Transformation: Uruguayan Exiles and the Latin American Human Rights Networks, 1967-1984. New York: Routledge, 2005.

Menjivar, Cecilia. Fragmented Ties. Salvadoran Immigrant Networks in America. Berkeley: University of California Press, 2000 .

Mörner, Magnus. The expulsion of the Jesuits from Latin America. New York: Alfred A.Knopf, 1965. 
Montúfar y Coronado, Manuel. (c. 1832). Memorias para la historia de la Revolución de Centro América-Memorias de Jalapa. 4ta edición. Guatemala: Tipografía Sánchez \& de Guise, 1934.

Pessar, Patricia R. "Women's Political Consciousness and Empowerment in Local, National and Transnational Contexts: Guatemalan Refugees and Returnees". Identities 7 (4). 2001.

Prestes Massena, Andreia. "Entre Brasil e Moçambique: os caminhos percorridos no exílio". Estudios interdisciplinarios de América Latina y el Caribe 20 (1). 2009: 67-92.

Racine, Karen. "Introduction: National Identity Formation in an International Context". Fey, Ingrid E. y Racine, Karen (comps.). Strange Pilgrimages. Exile, Travel, and National Identity in Latin America, 18001990s. Wilmington: Scholarly Resources, 2000.

Rénique, José Luis. "Benjamín Vicuña Mackenna: exilio, historia y nación”. Ciberayllu. 18 october 2005. En: $<$ http://www.andes.missouri.edu/andes/ Especiales/JLRVicuna/JLR Vicuna1. html> [Consultado: 13 de mayo de 2009].

Rénique, José Luis. "Vicuña Mackenna”. 2006. En: <http://www.andes.missouri.edu/ andes/ Especiales/JLRVicuna/JLR_ Vicuna1.html> [Consultado: 11 Junio del 2006].

Rodríguez Elizondo, José. La pasión de Iñaki. Santiago: Editorial Andrés Bello, 1996.

Rollemberg, Denise. Exílio. Entre raízes e radares. Rio de Janeiro: Record, 1999.

Roniger, Luis. "Reflexiones sobre el exilio como tema de investigación". [Trabajo preparado para el Seminario internacional sobre historia y memoria de los exilios Latinoamericanos]. 8-10 de junio. Brasil: Universidad Federal Fluminense, 2009.

Roniger, Luis y Sznajder, Mario. The Legacy of Human Rights Violations in the Southern Cone. Oxford: Oxford University Press, 1999.

Roniger, Luis y Sznajder, Mario. "Los antecedentes coloniales del exilio político y su proyección en el siglo XIX". Estudios Interdisciplinarios de América Latina y el Caribe 18(2). 2008: 31-51.

Roniger, Luis y Yankelevich, Pablo. "Exilio y política en América Latina: nuevos estudios y avances teóricos". Estudios interdisciplinarios de América Latina y el Caribe 20 (1). 2009: 7-18.

Rumazo González, Alfonso. 8 grandes biografías. Caracas: Ediciones de la Presidencia de la República. Tomo II. 1993.

Said, Edward. "Reflections on Exile". Ferguson, R.; Gever, M.; Minh-Ha, T.T. and West, C. (eds.). Out There: Marginalization and Contemporary Cultures. Massachusetts: MIT Press, 1994.

Shnookal, Deborah and Muñiz, Marta (Comps.). José Martí Reader. Writings on the Americas. Melbourne y New York: Ocean Press, 1999.

Sznajder, Mario y Roniger, Luis. The Politics of Exile in Latin America. New York: Cambridge University Press, 2009.

Torres Caicedo, José María. Ensayos biográficos y de crítica literaria. Segunda serie. Paris, 1868.

Vargas Araya, Armando. Idearium Maceista. Junto con hazañas del General Antonio 
Maceo y sus mambises en Costa Rica, 1891-1895. San José: Editorial Juricentro, 2001.

Vásquez, Ana y Araujo, Ana María. Exils latinoamericains. La malediction d'Ulysse. Paris: CIEMI and L'Harmattan, 1988.

Velasco, Juan de. Historia del reino de Quito en la América Meridional. Caracas: Biblioteca de Ayacucho, 1981.

Vicuña Mackena, Benjamín. El ostracismo de los Carrera. Los jenerales Jose Miguel i Juan Jose, i el coronel Luis Carrera. Episodio de la independencia de SudAmerica. Santiago: Imprenta del Ferrocarril, 1857.

Vicuña Mackena, Benjamín. Ostracismo del general D. Bernardo O'Higgins, escrito sobre documentos inéditos $i$ noticias autenticas. Valparaíso: Imprenta i librería del Mercurio, 1860.

Vicuña Mackena, Benjamín. Páginas de mi diario durante tres años de viaje, 1853, 1854, 1855. Tomo 2. Santiago de Chile: Universidad de Chile, 1936.

Wright, Thomas C. y Oñate Zúñiga, Rody. "Chilean Political Exile". Latin American Perspectives 34 (4). 2007: 31-49.

Yankelevich, Pablo (Coord.). México, país refugio. Las experiencias de los exilios en el siglo $X X$. México: INAH- Plaza y Valdés, 2002.

Yankelevich, Pablo y Jensen, Silvina (cords.). Exilios. Destinos y experiencias bajo la dictadura militar. Buenos Aires: Libros del Zorzal, 2007. 
